\title{
Human rhinosporidiosis: still an elusive disease
}

\begin{abstract}
Santosh Kumar Swain*
Department of Otorhinolaryngology, IMS and SUM hospital, Siksha "O” Anusandhan University, Bhubaneswar,
\end{abstract} Odisha, India.

Received: 08 July 2020

Accepted: 05 August 2020

\section{*Correspondence:}

Santosh Kumar Swain,

E-mail: santoshvoltaire@yahoo.co.in

Copyright: () the author(s), publisher and licensee Medip Academy. This is an open-access article distributed under the terms of the Creative Commons Attribution Non-Commercial License, which permits unrestricted non-commercial use, distribution, and reproduction in any medium, provided the original work is properly cited.

\begin{abstract}
Rhinosporidiosis is a granulomatous infection of the mucous membrane caused by Rhinosporidium seeberi. It usually affects the nasal and nasopharyngeal mucosa but sometimes involve extra-nasal sites such as lips, buccal mucosa, palate, larynx, trachea, lacrimal sac, skin, scalp, penis, urethra, vulva and bone. The natural habitat of this organism is water and the infection probably spreads via trans-epithelial penetration. Histopathological examination confirms the diagnosis. The treatment of choice is complete surgical excision with cauterization of the base but the medical treatment shows limited efficacy. The patient of disseminated rhinosporidosis does not respond to the conventional treatment such as surgical excision and dapsone and with amphotericin B also proved futile result. This infection is usually overlooked, despite $R$. seeberi being endemic in tropical country like India. Due to the negligence in the diagnosis and taxonomic enigma of rhinosporidiosis, here we discuss the details of its epidemiology, etiopathology, clinical presentations, diagnosis and current treatment. Because rhinosporidiosis is relatively rare, we hope this review article will serve as aid and guide to the medical community for helping further research.
\end{abstract}

Keywords: Rhinosporidiosis, Rhinosporidium seeberi, Recurrence, Mesomycetozoea.

\section{INTRODUCTION}

Rhinosporidiosis is a granulomatous disease due to infection by Rhinosporidium seeberi. It causes chronic mucocutaneous manifestations of the nose and nasopharynx with multiple vascular lesions. ${ }^{1}$ It commonly affects the nose and nasopharynx along with reported involvement of extra-nasal locations such as oropharynx, larynx, trachea, bronchi, eye, skin, ear and genitourinary tract. It is difficult to culture the R. seeberi and its atypical cellular features have been responsible for its taxonomic enigma. Phylogenetic analysis proved that the etiological agent of rhinosporidiosis of human beings is $R$. seeberi, a member of the order Dermocystida in the class Mesomycetozoae. ${ }^{2}$ The taxonomy of this organism is always controversial. This disease is usually transmitted to humans by direct contact with spores by swimming in stagnant water, dust, infected clothing and fingers. Aquatic exposure is usually universal in almost all cases and transmitted through direct contact by stagnant water. Large number of rivers and lakes with high riparian populations are predisposing factors for rhinosporidiosis. Complete surgical excision and electrodessication are the treatment of choice. Medical treatment is controversial. The rarity and endemicity of this granulomatous disease has further complicated with several questions related to its remaining unanswered till date. Due to negligence of the diagnosis and lack of medical literature tempted us to write this review article for rhinosporidiosis.

\section{METHODS FOR LITERATURE SEARCH}

We conducted an electronic search of SCOPUS, Medline and PubMed databases for searching the published articles. The search term in the databases included rhinosporidiosis, clinical presentations of rhinosporidiosis, diagnosis and current treatment of 
rhinosporidiosis. The abstracts of the published articles are identified by this search method and other articles were identified manually from the citations. This review article reviews the epidemiology, etiopathology, clinical presentations and current management of rhinosporidiosis. This review article presents a baseline from where further prospective trials can be designed and help as spur for further research in this commonly encountered clinical entity in tropical countries.

\section{EPIDEMIOLOGY}

Rhinosporidiosis has been known since more than 100 years; however, its epidemiology is poorly defined in some countries. Tropical and subtropical countries are thought endemic areas. Rhinosporidiosis is a granulomatous disease caused by Rhinosporidium seeberi affecting the mucocutaneous part of the body in South Asia with majority of the cases reported in Sri Lanka and India. ${ }^{3}$ Rhinosporidium seeberi(Rhinosporidium kinealy) belongs to the phycomycetes class of fungi. The first case of rhinosporidiosis was reported in 1892 by Malbran of Buenos Aires, Argentina. ${ }^{4}$ Guellermo Seeber reported the first detailed account of rhinosporidiosis in $1900 .^{5}$ Ashworth first described the life cycle of this fungus. ${ }^{6}$ In 1964, Karunarthne published a detail review of rhinosporidiosis in the human being. ${ }^{7}$ Rhinosporidiosis is reported from around 70 countries including South Asia, Latin America and African countries although the highest incidence has been reported from India and Sri Lanka. In India, this disease is more in Tamil Nadu, Kerala, Odisha, West Bengal and Chhattisgarh. Rhinosporidiosis is commonly seen among people working with agricultural farms, sand and bathing in the stagnant water. ${ }^{8}$ In Africa, rhinosporidiosis has been found in Cameroon, Congo, Kenya, Malawi, South Africa, Tanzania, Uganda and Zambia. $^{9}$ In the United States and Europe, rhinosporidiosis is rarely found in human beings. ${ }^{10}$ It is more in the populations those performing daily activities in ponds, rivers and lakes.

\section{ETIOPATHOLOGY}

Rhinosporidiosis is a granulomatous disease caused by Rhinosporidium seeberi which has a confusing taxonomy ranging from fungi, parasite and bacterial till eventually considered as aquatic eukaryote on the basis of the comparison with aquatic organisms and genetic sequencing. ${ }^{11}$ Rhinosporidiosis is thought to be a waterborne disease and usually occurs after swimming in the stagnant freshwater ponds or lakes or rivers but it also seen in air or dust. ${ }^{12}$ The natural hosts for rhinosporidiosis are aquatic parasite such as fish and amphibians. ${ }^{13}$ Rhinosporidiosis is a tropical disease and the Rhinosporidium seeberi, an enigmatic microorganism with disputed taxonomy. $R$. seeberi has not been detected from the environment and has no natural host or reservoir, so difficult to classify. Originally it was considered as protozoan and finally a fungus. Currently it is classified as an aquatic mesomycetozoea(between fungi and animals) on the basis of phylogenetic analysis of $18 \mathrm{~S}$ rDNA. ${ }^{14}$ So, Rhinosporidium seeberi is classified as a prokaryote cyanobacterium of the genus Microcystitis, an eukaryote pathogen and belong to the class Mesomycetozoea and a fungus. ${ }^{15}$ Herr et al also showed that this organism belongs to the class of mesomycetozoea. ${ }^{16}$ This organism is an aquatic in nature and often difficult to isolate in the culture. Presently the $R$. seeberi is taxonomically placed in DRIP(Dermocystidium, Rosette agent, Ichthyophonus and Psorospermium) which is renamed as the Mesomycetozoea. ${ }^{17}$ The polymerase chain reaction(PCR) study of the R. seeberi by taking its 18Sr-RNA gene and sequencing of full length $18 \mathrm{~S}$ subunit states that it belongs to cluster with novel group of fish parasite called as Dermocystidium, Rossete agent, Istiophorus and Psorospermium clade near to the animal fungal divergence. $^{2}$

It commonly involves mucosa of the nasal mucosa, nasal floor and inferior turbinate. This disease is possibly transmitted by direct contact with spores through the dust, fingers or infected cloths and swimming in stagnant water. Sometimes it involve lacrimal sac and there are different schools of thoughts for possible route of spread in lacrimal sac involvement for rhinosporidiosis. Some authors think the lacrimal sac is affected by upward extension of the mass from the nasal cavity. ${ }^{18}$ Some other authors commented that the lacrimal sac cannot be affected via nasolacrimal duct as the lacrimal folds act as a valve for preventing the secretion from the nasal cavity upwards into the nasolacrimal duct. ${ }^{19}$

\section{LIFE CYCLE}

In 1923, Ashworth described the life cycle of the organisms causing rhinosporidiosis. The life cycle of Rhinosporidium seeberi is usually complicated. The mature form of this organism is called as sporangia which contains multiple sporangiospores. The trophocytes, the immature form of this organism is smaller and thinner than sporangia and does not possess endospores. Trophocyte is round or oval in shape with size of 7 to 8 microns. ${ }^{1}$ Trophocyte has vaculated cytoplasm and vesicular nucleus. In the trophocytes, fat globules and several proteins appear. When the size of the trophocytes is 50 microns, the first nuclear division occurs. Then the nuclear division continues and it reaches to 100 microns. Then cellulose is laid inside the trophocytes and gradually 200 nuclei form and each nucleus are surrounded with cytoplasm and develop into a spore. ${ }^{4}$ This will become sporangia and become mature. Sporangiospores are released when the organisms becomes mature and thereafter develop into trophocytes. This disease is usually transmitted by humans with direct contact to spores via dust, infected clothing or fingers and by swimming in stagnant water. Although there are large numbers of peoples staying in endemic zones, bathing in common ponds, only a few people develop this disease. This justifies the existence of the predisposing factors in 
the host. The mode of transmission of the infection is from the natural aquatic habitat to the traumatized epithelium. It can spread by auto-inoculation, hematogenous route or lymphatics. The majority of the rhinosporidiosis patients are from rural areas suggesting that pathogenesis of this disease is associated with water or soil for transmission. ${ }^{20}$

\section{CLINICAL PRESENTATIONS}

The rhinosporidiosis is common in males(4:1) with most common among age groups of 10 to 40 years. ${ }^{21}$ The risk factors for rhinosporidiosis are bathing or working in the contaminated stagnant water which harbors the infectious agents. The rhinosporidiosis lesions are polypoidal, granular and red in colour due to pronounced vascularity (Figure 1).

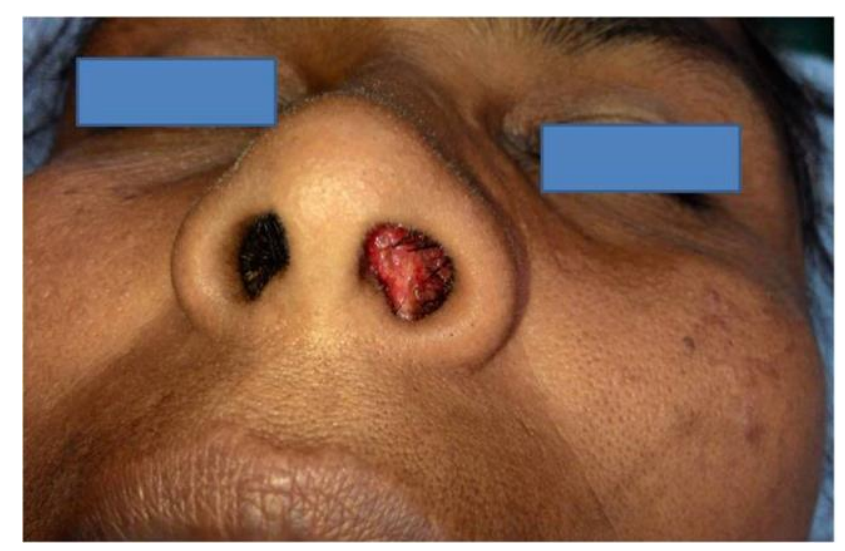

Figure 1: Rhinosporidiosis lesions.

The surface of the polypoidal mass contains whitish to yellowish pin head sized spots by the presence of sporangia. These types of presentations are also found in nasopharynx and lower aerodigestive tract. They presents with nasal obstruction and epistaxis. The patients of rhinosporidiosis often presents with polypoidal mass or vascular mass, sometimes pedunculated in nature seen in the nose $(70 \%)$, eye $(15 \%)$, throat, ear, upper respiratory tract, skin and genitalia in both male and female. Analysis of the blood grouping indicates that rhinosporidiosis is commonly found in blood group $\mathrm{O}$ and $\mathrm{AB} .^{22}$ However, the blood group among patients of rhinosporidiosis is variable to get any conclusion. The most common locations for occurrence include mucosa of the nasal septum, inferior turbinates and floor of the nasal cavity. ${ }^{23}$ Nose and nasopharynx are the common locations for rhinosporidiosis followed by the eye. The laryngeal and tracheal involvement occurs due to the bleeding from nasal lesions. Nasopharyngeal rhinosporidiosis in adolescent age often mimic to the juvenile nasopharyngeal angiofibroma. Rhinosporidiosis can affect lung, urethra, genitalia, lacrimal sac and bones but rarely seen. ${ }^{24}$ Rhinosporidiosis involving trachea of tencreate diagnostic and therapeutic challenges to the clinicians. This is due to friable and vascular nature of the mass which often create a difficult situation for removal of the mass. It also may lead to airway compromise. Disseminated skin lesions are extremely rare and often associated with mucosal lesions. Cutaneous lesion without involvement of the mucosal membrane is uncommon in clinical practice. Rhinosporidiosis has multifaceted presentations over the skin. Dermatological lesions have pedunculated or sessile types of growths, verruca vulgaris like lesions, cutaneous horns, shiny globular bulging and cystic swellings. The clinical differential diagnoses are verrucae vulgaris, granuloma pyogenicum and verrucous tuberculosis. ${ }^{25}$

Sometimes rhinosporidiosis involves parotid gland and its duct. One study suggests that possibility of natural patulous and everted anatomy of the orifice of the parotid duct inside the oral cavity may promote a quick passage of the spores into the duct during washing the mouth cavity in pond water leads to development of the disease. ${ }^{26}$ Although involvement of rhinosporidiosis in the parotid gland and its duct are extremely rare, there is handful cases(around 5 cases) reported worldwide. ${ }^{8}$ Extra-nasal involvements of rhinosporidiosis are rare and it hinders the diagnosis at the early stage of the disease because of the less familiarity of the sites and symptoms. ${ }^{27}$ Detail distributions of socio-demographic parameters associated with rhinosporidiosis(Table 1). ${ }^{28}$

\section{DIAGNOSIS}

As the Rhinosporidium seeberi cannot be grown in culture, the histopathological examination is the gold standard. ${ }^{29}$ Giemsa imprinted smears and fine needle aspirate with $10 \% \mathrm{KOH}$ staining are helpful for the diagnosis. Histopathological study reveals hyperplastic epithelium with chronic inflammatory cells like plasma cells and lymphocytes along with foreign body giant cells. The characteristics sporangia with different stages of maturations are found as globular cysts of different $\operatorname{sizes}(50$ to $1000 \mu \mathrm{m}$ in diameter), lined with a well defined wall and contains numerous endospores with diameter of 5 to $10 \mu \mathrm{m}$ surrounded by inflammatory cells (Figure 2). Gomori methenamine silver, periodic acid Schiff, mucicarmine, Grocott stain and hematoxylin \& eosin stain are helpful to stain positively to the sporangia and endospores. ${ }^{30}$ The periodic acid-Schiff stain is useful to discriminate between the endospores and epithelial cells, particularly from the nasopharynx as the endospores stain markedly magneta, whereas the epithelial cells are periodic acid-Schiff negatively. ${ }^{31}$ Mucicarmine stain is helpful in differentiating Coccidioides immitis, as sporangia and endospores of this organism do not stain positively. Coccidiomycotic lesions may create confusion with rhinosporidiosis during histopathologic and cytologic evaluation as former has similar mature stages of large, thick walled spherical structures possessing the endospores. Differentiation can also be occurred by hematoxylin and eosin stain as the endospores of $R$. seeberi are larger and more numerous in compare to $C$. immitis and $C$.immitis can be cultures but $R$. seeberi cannot. ${ }^{30}$ Diagnostic nasal endoscopy helps to 
assess the exact location of the rhinosporidiosis and its extent. The definite diagnosis of Rhinosporidiosis is based on the histopathological examination with identification of the organism in it different stages along with stromal and inflammatory response of the host. ${ }^{32}$ The molecular techniques have recently identified the organism as an aquatic protistan parasite in the Mesomycetozoea class causing rhinosporidiosis. The diagnosis is established by an advanced molecular technique such as PCR or 16s RNN or simply by observing characteristic mucosal appearance on histopathological study. ${ }^{33,34} \mathrm{CT}$ scan and MRI are helpful to assess the site of the rhinosporidiosis and its extent. Imaging is also useful to rule out other sinonasal pathology.

Table 1: Distribution of rhinosporidiosis patients according to different socio-demographic parameters. $^{28}$

\begin{tabular}{|ll|}
\hline Parameters & Percentage (\%) \\
\hline Gender & 58.97 \\
\hline Male & 41.03 \\
\hline Female & \\
\hline Residence & 82.05 \\
\hline Rural area & 17.95 \\
\hline Urban area & \\
\hline Religion & 79.49 \\
\hline Hindu & 20.51 \\
\hline Muslim & \\
\hline Caste & 43.59 \\
\hline General & 56.41 \\
\hline Backward class & \\
\hline Age & 46.15 \\
\hline$<15$ years & 53.85 \\
\hline$\geq 15$ years & \\
\hline Occupation & 66.67 \\
\hline Student/house wife & 33.33 \\
\hline Agriculture/Labor & \\
\hline Cattle farming & 58.97 \\
\hline Present & 41.03 \\
\hline Absent & \\
\hline Family history of contact & 12.82 \\
\hline Present & 87.18 \\
\hline Absent & \\
\hline Disease status & 87.18 \\
\hline Fresh & 12.82 \\
\hline Recurrent & 38.46 \\
\hline Symptoms & 35.90 \\
\hline Nasal obstruction only & 25.64 \\
\hline Nasal bleeding only & 15.38 \\
\hline Both & 84.62 \\
\hline Body parts involved other than nose & \\
\hline Yes & \\
\hline No & \\
\hline & \\
\hline
\end{tabular}

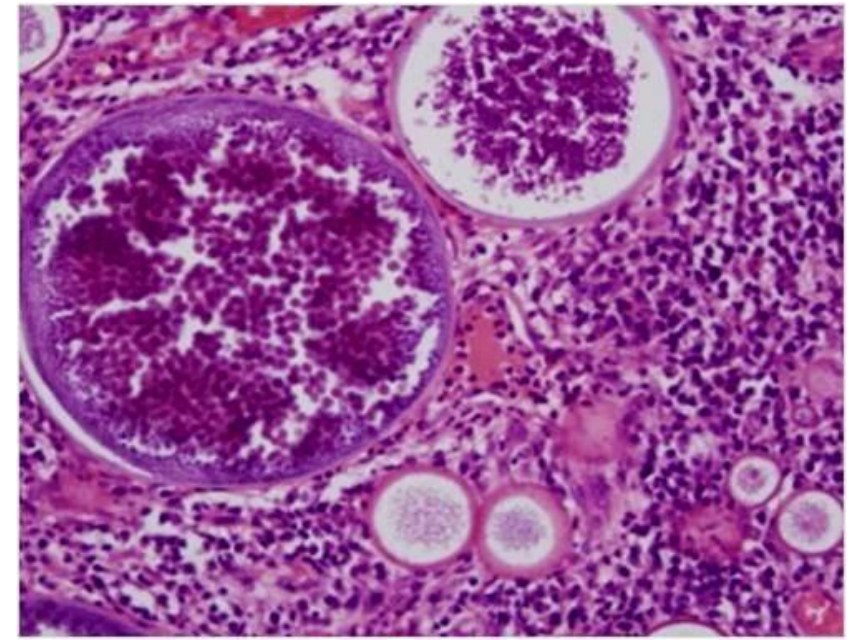

Figure 2: Histopathological study.

\section{TREATMENT}

The medical treatments such as antifungal and/or antimicrobial drugs are not effective against $R$. seeberi. The mode of the treatment is always is surgical excision. Complete excision of the mass with electrocoagulation of the base is treatment of choice ". Availability of the high definition camera and very good endoscopes are making easy to address the extensive lesions of the rhinosporidiosis in the nose, nasopharynx even skull base area and naso-orbital areas. Some studies say an endonasal endoscopic approach may leads to seeding of the spore at the incision site. ${ }^{35}$ However, route of surgical approach does not make much difference provided that the removal is wide and complete. However, the multidisciplinary approach always is good for handling the extensive lesions beyond the nose and nasopharynx. Recurrences are known to happen due to spillage of the endospores in the adjacent tissue or incomplete excision of the mass/lesion. The ablation technique such as coblation is a promising tool for surgical resection of the recurrent cases of rhinosporidiosis. This technique helps to reduce the chance of contamination of the surrounding tissues and prevents the auto-inoculations. ${ }^{36}$ Laser is also useful tool for adequate cauterization along with good hemostasis so reduce chance of complications and recurrence. ${ }^{37} \mathrm{CO} 2$ laser is helpful for lesions over nasal septum up to the choana and roof of the nasopharynx and it minimizes the chance of recurrence. Laser can be used as an additional tool during surgery and appropriate measures should be taken so that the lesions are removed completely and the attachments are cauterized or laserised following removal of the disease bulk. ${ }^{38}$

Antifungal drugs such as griseofulvin and amphotericin B are tried in rhinosporidiosis without much success. The only drug which has some benefit is Dapsone which arrests the maturation of the sporangia and enhances the fibrosis in the stroma, which often prescribed as adjunct to the surgical excision. ${ }^{39}$ Most patients of rhinosporidiosis with localized lesion respond to the 
treatment of Dapsone following surgical removal of the mass. Tablet Dapsone is usually recommended for 1 to 2 years for avoiding recurrence and dissemination of the lesions. ${ }^{32}$ The medical treatment in rhinosporidiosis shows limited efficacy due to the presence of large number of fungal elements when compared with vascular components and these fungal components are also larger than the phagocytic cells of immunoresponse. ${ }^{40}$ Again the impenetratability of the sporangia wall is responsible for failure of the medications and immune response. ${ }^{39,41}$ Patients of disseminated rhinosporidiosis usually do not respond to conventional treatment such as dapsone and surgical excision and also treatment with amphotericin B also futile. Swimmers and persons those are frequent visitors to the water bodies should maintain safety precautions as $R$. seebri may be transferred through the cut wounds.

\section{PROGNOSIS}

Observations on the rhinosporidiosis suggests that limited disease has better prognosis whereas involvement of more than one site like subcutaneous spread and lacrimocutaneous fistula have guarded prognosis. This disease is notorious for its recurrence. Recurrence can occur at the primary site or at the anatomically contagious area. Recurrence of the rhinosporidiosis can occur because of the spillage of the endospores into adjacent epithelium or tissues or due to incomplete removal of the base of the stalk during excision of the mass. The recurrence after complete excision of the rhinosporidiosis might be explained by decreasing of the anti-rhinosporidial cell mediated immunity mediated by switch from Th1 to Th2. ${ }^{11}$ It occasionally disseminates to the distant sites from initial focus such as upper respiratory tract. ${ }^{42,43}$ One study documented 32 patients of rhinosporidiosis treated with dapsone after surgical excision showed no recurrence in $71.4 \%$ of patients in 3 years follow up. ${ }^{44}$

\section{CONCLUSION}

The prevalence of rhinosporidiosis is very high in South Asia particularly India, mostly in south and central part of the India. The common sites affected by it are nasal cavity, nasopharynx and oropharynx. The causative organism i.e. Rhinosporidium seeberi is difficult to culture and the diagnosis is based on microscopy and histological examination of the lesion. As India being an endemic region, rhinosporidiosis should be kept in mind when seeing the patients with nasal mass or in any part of the head and neck area. The treatment of choice is meticulous, complete and wide surgical excision of the lesion followed by electrocauterisation of the base which help to ablate the recurrence. The recurrence is often due to spillage of endospores on the surrounding mucosa. This disease has high chance of recurrence after surgery and occasionally disseminates from the initial origin. Early detection of the disease and prompt treatment will reduce the associated morbidity and mortality due to this disease. In view of the molecular diagnosis of this organism, further research is required to discover the effective treatment of the rhinosporidiosis.

Funding: No funding sources

Conflict of interest: None declared

Ethical approval: Not required

\section{REFERENCES}

1. Kaushal S, Mathur SR, Malik SR, Ramah M. Disseminated cutaneous, laryngeal, nasopharyngeal and recurrent obstructive nasal rhinosporidiosis in an immunocompetent adult: a case report and review of literature. Int J Dermatol. 2011;50:340-2.

2. Herr RA, Ajello L, Taylor JW, Arseculeratne SN, Mendoza L. Phylogenetic analysis of Rhinosporidium seeberi's $18 \mathrm{~S}$ small-sub unit ribosomal DNA groups this pathogen among members of the protistan Mesomycetozoa clade. J Clin Microbiol. 1999;37:2750-4.

3. Lupi O, Tyring SK, McGinnis MR. Tropical dermatology, fungal tropical disease. J Am Acad Dermatol. 2005;53:931.

4. Kameswaran S, LakshmananM. Rhinosporidiosis. ln: Karncswaran S, Laksluna nan $\mathrm{M}$, eds . ENT Disorders in a Tropieal Environment. Chennai, India: MERF Publications. 1999:19-34.

5. Seeber GR. Un nuevo esporozoario parasito de 1 hombre: Doscasos eneon trades en polipas nasales [thesis]. Bueno sAires: Universidad Nacional de Buenos Aires. 1900.

6. Ashworth JH. Rhinosporidiumsccbcri (Wernickc, 1903) with special refere nce to its sporulation and affini ties. Trans R Soe Edinburgh. 1923;53:301-42.

7. Karuna ratne WA. Rhinos poridiosis in Man. London. Athlone Press;1964.

8. Rameshkumar A, Gnanaselvi UP, Dineshkumar T, Raghuram PH, Bharanidharan R, Rajkumar K. Rhinosporidiosis presenting as a facial swelling: a case report. Journal of international oral health. 2015;7(2):58.

9. Salazar Campos MC, Surka J, Garcia Jardon M, Bustamante N. Ocular rhinosporidiosis. S Afr Med J. 2005;95:950-2.

10. Sudasinghe T, Rajapakse RP, Perera NA, Kumarasiri PV, Eriyagama NB, Arseculeratne SN. The regional sero-epidemiology of rhinosporidiosis in Sri Lankan humans and animals. Acta Trop. 2011;120:72-81.

11. Arseculeratne SN. Rhinosporidiosis: what is the cause?. Curr Opin Infect Dis. 2005;18(2):113-8.

12. Kuriakose ET. Oculosporidiosis: rhinosporidiosis of the eye. Br J Ophthalmol. 1963;47:346-9.

13. Mukherjee B, Mohan A, Sumathi V, Biswas J. Infestation of the lacrimal sac by Rhinosporidium Seeberi: a clinicopathological case report. Indian J Ophthalmol. 2013;61:588-90.

14. Vilela R, Mendoza L. The taxonomy and phylogenetics of the human and animal pathogen Rhinosporidium seeberi: a critical review. Rev Iberoam Micol. 2012;29:185-99. 
15. Alhuwalia KB, Maheshwari N, Deka RC. Rhinosporidiosis: a study that resolves etiologic controversies. Am J Rhinol. 1997;11:479-83.

16. Herr RA, Ajello L, Taylor JW, Arseculeratne SN, Mendoza L. Phylogenetic analysis of Rhinosporidium seeberi's $18 \mathrm{~S}$ small-sub unit ribosomal DNA groups this pathogen among members of the protistan Mesomycetozoa clade. J Clin Microbiol. 1999;37:2750-4.

17. Herr RA, Ajello L, Taylor JW, Arseculeratne SN, Mendoza L. Phylogenetic analysis of Rhinosporidium seeberi's $18 \mathrm{~S}$ small-subunit ribosomal DNA groups this pathogen among members of the protoctistan mesomycetozoa clade. J Clin Microbiol. 1999;37:2750-4.

18. Varshney S, Bist SS, Gupta P, Gupta N, Bhatia R. Lacrimal sac diverticulum due to rhinosporidiosis. Indian J Otolaryngol Head Neck Surg. 2007;59:3536.

19. David SS, Sivaramasubrahmanyam P. Ocular rhinosporidiosis, a study of twenty cases. Indian J Ophthalmol. 1973;21:204-7.

20. Rath R, Baig SA, Debata T. Rhinosporidiosis presenting as an oropharyngeal mass: a clinical predicament? J Nat Sci Biol Med. 2015;6:241-5.

21. Tiwari D, Bakshi SS, Das S, Gopalakrishnan S. Disseminated rhinosporidiosis. Arch Med Health Sci.2019;7:84-6.

22. Nayak S, Rout TK, Acharjya B, Patra MK. Subcutaneous rhinosporidiosis. Indian J Dermatol. 2008;53:41-3.

23. Prabhu SM, Irodi A, Khiangte HL, Rupa V, Naina P. Imaging features of rhinosporidiosis on contrast CT. Indian J Radiol Imaging. 2013;23:212-8.

24. Saha J, Basu AJ, Sen I, Sinha R, Bhandari AK, Mondal S. Atypical presentations of rhinosporidiosis: A clinical dilemma? Indian J Otolaryngol Head Neck Surg. 2011;63:243-6.

25. Kumari R, Laxmisha C, Thappa DM. Disseminated cutaneous rhinosporidiosis. Dermatol Online J. 2005;11:19.

26. Mandalik GS. A record of rhinosporidial polyp: with some observation on mode of infection. Indian Med Gaz. 1937;72:143-7.

27. Panda S, Lenka S, Padhiary SK, Sahoo SR, Srivastava G. Rhinosporidiosis in the parotid duct: a rare case report. J Investig Clin Dent. 2013; 4(4):271-4.

28. Dutta S, Haldar D, Dutta M, Barik S, Biswas KD, Sinha R. Socio-demographic correlates of rhinosporidiosis: A hospital-based epidemiologic study in Purulia, India. Indian Journal of Otolaryngology and Head \& Neck Surgery. 2017; 69(1):108-12.

29. Arseculeratne SN. Recent advances in rhinosporidiosis and Rhinosporidium seeberi. Indian J Med Microbiol. 2002;20:119-31.
30. Sinha A, Phukan JP, Bandyopadhyay G, Sengupta S, Bose K, Mondal RK, et al. Clinicopathological study of rhinosporidiosis with special reference to cytodiagnosis. Journal of Cytology/Indian Academy of Cytologists. 2012;29(4):246.

31. Arseculeratne SN. Recent advances in rhinosporidiosis and Rhinosporidium seeberi. Indian J Med Microbiol. 2002;20:119-31.

32. De Silva NR, Huegel H, Huegel DN, Arseculeratne SN, Kumarasiri R, Gunawardena S, et al. Cellmediated immune responses (CMIR) in human rhinosporidiosis. Mycopathologia. 2001;152(2):59.

33. Singh CA, Sakthivel P. Rhinosporidiosis. N Engl J Med. 2019;380(14):1359.

34. Swain SK, Behera IC, Mohanty JN. Mucormycosis in head-and-neck region-Our experiences at a tertiary care teaching hospital of Eastern India. Annals of Indian Academy of Otorhinolaryngology Head and Neck Surgery. 2019;3(2):58.

35. Nerurkar NK, Bradoo RA, Joshi AA, Shah J, Tandon S. Lacrimal sac rhinosporidiosis: a case report. Am J Otolaryngol. 2004;25:423-5.

36. Khan I, Gogia S, Agarwal A, Swaroop A. Recurrent Rhinosporidiosis: Coblation Assisted Surgical Resection-A Novel Approach in Management. Case reports in otolaryngology. 2014;2014.

37. Vinod MK, Kaur A, Devgan K, Singh J. Rare case of rhinosporidiosis: a case report from Jammu. International Journal of Otorhinolaryngology and Head and Neck Surgery. 2017;3(1):148.

38. Tiwari R. Rhinosporidiosis: A Riddled Disease of Man and Animals. Advances in Animal and Veterinary Sciences. 2015;3(2):55.

39. Job A, Venkateswaran S, Mathan M, Krishnaswami H, Raman R. Medical therapy of rhinosporidiosis with dapsone. J Laryngol Otol. 1993;107 (9):809-12.

40. Madke B, Mahajan S, Kharkar V, Chikhalkar S, Khopkar U. Disseminated cutaneous with nasopharyngeal rhinosporidiosis: light microscopy changes following dapsone therapy. Australas J Dermatol. 2011;52:4-6.

41. Swain SK, Debta P, Sahu MC, Mohanty JN. Otomycosis due to Aspergillus versicolor. International Journal of Health \& Allied Sciences. 2020;9(2):192.

42. Swain SK, Sahu MC, Debdta P, Baisakh MR. Primary fungal laryngitis: An overlooked clinical entity. Apollo Med. 2019;16:11-5.

43. Swain SK, Nahak B,Sahu MC.Fungal laryngitis in asthmatic boy treated with inhalatory corticosteroids:A Case Report.Pediatria polska. 2017;92:453-6.

44. Nair KK. Clinical trial of diaminodiphenylsulphone [DDS] in nasal and nasopharyngeal rhinosporidiosis. Laryngoscope.1979;89:291-5.

Cite this article as: Swain SK. Human

rhinosporidiosis: still an elusive disease. Int $\mathrm{J}$ Otorhinolaryngol Head Neck Surg. 2020;6(9):174752. 